\title{
GCU
}

Glasgow Caledonian

University

University for the Common Good

\section{The role of family centres in reducing social isolation in deprived communities}

Mercer, Fiona; Darbyshire, Chris; Finlayson, Janet; Kettle, Martin; Dickson, Adele

Published in:

Child and Family Social Work

DOI:

$10.1111 / \mathrm{cfs} .12742$

Publication date:

2020

Document Version

Author accepted manuscript

Link to publication in ResearchOnline

Citation for published version (Harvard):

Mercer, F, Darbyshire, C, Finlayson, J, Kettle, M \& Dickson, A 2020, 'The role of family centres in reducing social isolation in deprived communities', Child and Family Social Work, vol. 25, no. 3, pp. 674-682.

https://doi.org/10.1111/cfs.12742

\section{General rights}

Copyright and moral rights for the publications made accessible in the public portal are retained by the authors and/or other copyright owners and it is a condition of accessing publications that users recognise and abide by the legal requirements associated with these rights.

Take down policy

If you believe that this document breaches copyright please view our takedown policy at https://edshare.gcu.ac.uk/id/eprint/5179 for details of how to contact us. 


\begin{abstract}
Social exclusion and isolation are worldwide social and health concerns with negative effects becoming exacerbated in deprived communities. There is limited understanding related to the role of community-based centres in reducing social exclusion and isolation so the aim of this research was to explore the role one family centre had in improving social inclusion in a deprived community in Glasgow, Scotland. Interpretative Phenomenological Analysis (IPA) was utilised to analyse interviews from 10 parents to explore their lived experiences of creating and developing social networks through family centre attendance. Findings indicate that attending the family centre positively impacted on social inclusion and social support for all parents interviewed. Relationships created in the centre were proposed as being meaningful, non-judgemental and produced social capital - rooted in reciprocity and trust. Findings can inform services which aim to reduce social isolation in deprived communities.
\end{abstract}

Key words: 'social networks'; 'social isolation'; 'interpretative phenomenological analysis'; 'family centre'; 'social exclusion' 


\section{INTRODUCTION}

Around $19 \%$ of the Scottish population live in relative poverty after housing costs (Scottish Government, 2018) and in Glasgow almost half the population live concentrated in the $20 \%$ most deprived areas (Scottish Government, 2016). This means a considerable percentage of the population face disparities related to poverty, including social exclusion and isolation (Glasgow Centre for Population Health, 2011). Even after controlling for deprivation, citizens experience more significant disparities such as lower life expectancy in comparison to the rest of the United Kingdom and Europe - an outcome known as 'The Glasgow Effect' (Lewis, 2017). The Glasgow Effect is partly characterised by social inequalities related to deprivation such as social exclusion and isolation (Glasgow Centre for Population Health, 2011) and in the most deprived areas of the city the levels of social isolation reported were double that of the more affluent areas (Glasgow Centre for Population Health, 2011). These findings support evidence of the relationship between deprivation and social isolation (Hawton et al, 2011), which has been termed the 'socio-economic gradient in loneliness' (Demakakos et al, 2006). Recently the Scottish Government (2018) identified communities as knowing 'what is best for them' and rooted strategy to reduce loneliness in community empowerment. Between 2018 and 2020, £1 million was invested to build on 'collective capacity to implement strategy' following previous findings which identified the pivotal role of community-based organisations in reducing social isolation (Scottish Government, 2018).

Social exclusion and social isolation are often used interchangeably but there are subtle differences. Social exclusion is generally understood as an individual being unable to participate in economic, social, political and cultural life within society (United Nations, 2016). This differs from social isolation which is more aligned with the absence of "quality and/or quantity of social relationships' (Smith \& Christakis, 2008). The negative effects of social isolation including segregation from social, economic, political and cultural systems within society can be recognised as social exclusion (Wilkinson \& Marmot, 2003). Over the past 20 years tackling social exclusion and social isolation (Scottish Government, 2018) has 
been a key agenda for the Scottish Government (Cook, 2012). Previous strategies to address social exclusion have focused on drives to engage individuals in the labour market to overcome poverty but this is less effective as levels of in-work poverty rise (Scottish Government, 2016). Social exclusion and isolation in Scotland are country-wide but tend to be concentrated in urban areas where there are high levels of deprivation (Scottish Government, 2011). In cities with complex and inter-related multiple levels of deprivation being socially connected has been identified as essential for facilitating individuals to meet basic daily needs and live meaningful and satisfactory lives (Cole, Batty \& Green, 2011).

It is not the quantity of social networks, rather the quality of these relationships which are important in making an individual feel socially integrated and supported (Cacioppo \& Hawkley, 2009). Social networks offer numerous functions, including selfesteem; sense of identity; and social support (Cattell, 2001). Closely related to social networks is the creation of social capital. Social capital is a social resource which is created within social networks and is related to the collective benefits from the relationship, such as trust and reciprocal support (Putnam, 2000). Social capital is not a physical resource and does not belong to the individual but is instead a resource which is created within the structure of social networks (Coleman, 1988).

Deprivation, social status and associated inequalities have been identified as being intergenerationally transmitted (Morrison et al, 2014; Kirk, 2003) highlighting the importance of exploring family support. Effective family support has been described as services and resources which provide comprehensive support and address interconnected needs (Whittaker et al, 2014). Community based family support is a key source of informal and professional support and over the past decade there has been a movement towards providing support through centre-based practices (Warren-Adamson, 2006), with the aim of providing support which is integrated and varied for families.

Whittaker et al (2014) defined family centres as being a 'social resource' which are essential in providing parents with the opportunity to socialise with other parents in the community (Donetto \& Maben, 2014). This supports previous findings from Kirk (2003) 
who proposed centres as being 'an essential part of every-day life for an increasing number of Scottish parents and children'. Family centres were found to widen parental social networks, build upon parent's confidence in creating and developing social relationships, positively impact on levels of formal and informal support and increase feelings of social inclusion in the community (Kirk, 2003). Benefits of family centres also include helping parents foster a sense of socially situated autonomy as they can identify, choose and participate in support which they view as suiting their needs (Donetto \& Maben, 2014). Additionally, family centres can also offer support to families who do not meet thresholds for statutory intervention (Sheppard, 2012 meaning that parents can be supported preventatively, reducing the need for crisis intervention.

Family centres are an essential component of family support (Warren-Adamson, 2006) however it is difficult to define which specific services make a positive impact. Even with legislation providing a framework for services offered in family centres, no two centres are alike and they are diverse in terms of service provision and delivery (Lewis, Cuthbert \& Sarre, 2011). Furthermore, it might not be the services provided which impacts positively but instead the strength-based approach utilised which builds capacity and autonomy within families. The nature of family life is complex meaning that there are many factors that can influence change in family life which may not be linked directly to the support provided. To gain an understanding of the value of family centres it is essential to conduct research which can explore this from the perspectives of parents.

\section{RESEARCH AIM AND OBJECTIVES}

The aim of this research was to explore parents' lived experiences of attending a family centre and the impact this has on feelings of social inclusion. Research objectives were to:

1. Explore the impact of the family centre on social networks.

2. Explore the kinds of relationships created through family centre attendance.

3. Identify properties of strong friendships which had been created in the family centre. 


\section{METHOD}

\section{Research Setting}

Research was undertaken in one family centre in the East end of Glasgow. This area is the most deprived decile in the city (Scottish Government, 2016). The centre was run by a third sector organisation which provides social support to vulnerable people throughout Scotland. The family centre provided the local community with a range of support and all resources differed in terms of formality and intervention. The centre offered support for children, parents and families and provided a drop-in space in addition to structured groups.

\section{Qualitative Approach and Rationale}

Social inclusion is essential for individuals' health, well-being and social lives (Cattell, 2001; Wilks \& Croom, 2008; Umberson \& Montez, 2010) however there is a gap within the literature relating to the lived experience and meaning attached to creating and developing social networks. Interpretative Phenomenological Analysis (IPA) was utilised as the methodology affords a rich, detailed insight of parents' experiences of family centre attendance and the meaning making attached to these experiences (Smith, Flowers \& Larkin, 2009).

\section{Ethical Approval}

All documentation was approved by the family centre gatekeepers before submission to Glasgow Caledonian University's School of Health and Life Sciences Research Ethics Committee. Full ethical approval was granted.

\section{Participants and Procedure}

Following IPA's idiographic underpinnings (Smith et al, 2009) a small, homogenous purposive sample of 10 parents attending the family centre took part in the research. Nine participants were female and were aged between mid-20's and mid-40's. The family centre was situated in a small community and most attendees knew each other very well so demographic details 
have purposely been reported in only very general terms to protect participant anonymity. Additionally, all participants were given pseudonyms and all other identifiable information was changed. Information about the research and the contact details of the researcher (lead author) were provided to parents via information leaflets, however the lead author was in the family centre weekly and most parents tended to ask any questions they had about the study face-toface. Willing participants contacted the lead researcher to express their interest in partaking and a mutually convenient time was arranged for interviews to commence.

Two reference groups (total $\mathrm{N}=14$ ) were facilitated prior to conducting interviews. The aim of these groups was to have discussion with parents about the family centre in general, explore related issues they thought would be important to discuss in an interview and following this, co-produce an interview schedule. Aligned with theoretical underpinnings, researchers using IPA should minimise making assumptions and by having service user involvement (SUI) at this stage topics included in the interview schedule were thought to be a more accurate representation of what would be meaningful and valuable to parents to discuss than if they had been solely reliant upon researcher assumptions.

Individual interviews were then conducted using the interview schedule co-created however not all parents who took part in the reference groups also took part in the interviews. The inclusion criteria were that participants had to be over 16 years; have a child under the age of 12 years; and attend the family centre. Interviews took place in a quiet private room within the family centre and lasted on average 70 minutes. All interviews were audio recorded and transcribed verbatim. The number of interviews was not set a-priori however after 10 interviews theoretical saturation has been reached and no new themes were emerging from the data. The topic guide was designed to be flexible with typical questions including: 'can you tell me about your typical day in the family centre?' with the interviewer probing for further information and seeking clarification wherever necessary. 


\section{Data Analysis}

IPA does not have a concrete analytic process however there are some essential components suggested by Smith et al (2009) which were followed in the current study: exploratory coding; emergent themes; and idiographic focus. After transcription the researchers read and re-read the interviews and begun exploratory coding. Exploratory coding identifies how an individual speaks, thinks and understands experience (Smith et al, 2009) and was conducted line by line in order to 'open up data' (Smith et al, 2009). Following exploratory coding, the research team moved towards engaging with initial codes and notes instead of the transcript in order to maintain the depth of analysis whilst also reducing the volume of data.

Three levels of coding were utilised: descriptive coding; linguistic coding; and interrogative coding, with each level becoming increasingly interpretative. The first level was descriptive coding whereby the content of the data was described. Following this, linguistic coding was used to explore linguistic properties of the data in more detail, including metaphor use and functional aspects of language. Then the research team began to engage with interrogative coding and begun asking questions of the data in order to develop questions about meaning behind participants' words (Smith et al, 2009). Engaging with interrogative coding facilitated a 'phenomenological attitude' and analysis became reflective of both the participant's words and the researcher's interpretations (Smith et al, 2009). Emergent themes were usually an abstraction of exploratory codes but were occasionally reflective of participant's verbatim phrasing (Smith et al, 2009). Emergent themes were created, reflected upon in relation to the whole transcript and revisited to develop or change. This helped retain the complexity and detail from the exploratory codes whilst simultaneously moving to a higher level of abstraction which was more dependent on researcher interpretation. Triangulation was engaged with through peer checking in order to assess that analysis was accurate, trustworthy and high-quality.

The idiographic nature of IPA meant that analysis was not limited to making only general claims for the group (Smith, 2004) and this created a deeper understanding of the essence of individual parent's experience. Following this, individual experience was then examined in 
relation to the whole data set (Smith et al, 2009). From this, patterns across the data set were identified and this helped to solidify themes identified in idiographic analysis (Smith et al, 2009). Three main themes emerged from parents' interviews. Overarching themes identified the valuable role the family centre in parent's social integration. Relationships which were created in the centre were identified by parents as being qualitatively different to relationships created outside the centre and strong friendships created in the centre were rooted in trust and reciprocity. 


\section{FINDINGS}

\section{Theme One: Family Centres Role in Social Integration}

\section{Subtheme One: Transient Nature of Isolation}

All interviewees identified that they had felt isolated before coming to the family centre, so it was important to explore how relationshipswere first created but also how they were integrated into parents' lives beyond the family centre walls. Parents identified the centre as providing an opportunity to meet friends which was not available elsewhere in the community.

\footnotetext{
"As weeks were getting on you built up a kind of a relationship with the women in the groups and you know you were looking forward to the Friday to hear other people's stories. Rather than just about you. Some of the weeks it was great to listen to other folk's stories - that I wasn't alone in this." (Hayley)
}

A common way for parents to create and develop relationships was through attending groups which Hayley identified as a temporal process - "as the weeks were getting on." Hayley attended a mother's support group and week by week members shared their own experiences and were supported by each other. This meant that members could receive support or provide support and occasionally both happened within the same session. The term "build up" emphasised growth in friendships and regular attendance at the group was an investment into her social network. Attending the group provided parents with the chance to hear stories about others' experiences and this provided Hayley with a sense of relief in two ways - through realising she was not alone in her own experiences and providing her with a break from ruminating about her own worries.

Additionally, past experiences of support from the centre shaped parents' future expectations of support and this was reassuring and comforting for many parents. 
"Em, it makes you feel a bit more confident as well that if you are ever depressed you are not going to sit and struggle yourself, there is always going to be somebody there who is looking out for you." (Leah)

Leah had experience isolation during previous struggles but after creating friendships within the centre she felt she would no longer be isolated when she needed support in the future. It was common for parents to consider the friendships they had made as being lasting sources of support and this became especially apparent in those relationships which had been integrated into their lives out with the centre. Leah proposed "there is always going to be someone there who is looking out for you" which provokes imagery likened to that guardian angels. Leah felt protected by her friends in the centre and this mirrored a common theme which proposed relationships created in the family centre as being a kind of safety net for parents.

\section{Subtheme Two: Turning Points}

Parents commonly felt isolation in two ways. Firstly, they felt socially isolated and secondly, they felt experientially isolated.

I didn't feel isolated anymore. I didn't feel like I was in this complete abyss of being alone. And, that's when I started to realise that if there's six of us sitting in a room, how many other people are out there? (Amanda)

Before integrating in the groups, it was common for parents to perceive that they were isolated in terms of their experiences and emotions, and this was especially prominent in mothers' experiences of post-natal depression. In this extract Amanda describes the moment she had the realisation that if she was feeling this way, many others would be too and becoming integrated with social networks was essential in facilitating this turning point. Amanda discusses being in a "complete abyss of being alone" and this language portrays a seemingly endless isolation, which is in contrast to the sense of togetherness and belonging in the group which Amanda portrays - "six of us". Amanda identifies herself as being part of the 
collective and included; something which she would not have been able to do before coming to the family centre.

Creating friendships also provided parents with new perspectives which shaped how they understood their life-worlds.

"And that was a big turning point for me was coming here when I was like that. Know what I mean? Because the boys were really supportive and everything else when I came. They didn't judge me. They asked me what was wrong, what was going on and everything else but other than that, they were fine with it." (Greg)

Greg had a visible health condition which he said others judged him by however he felt less judged in the family centre and this was a finding which was echoed by over half the parents. It wasn't that parents in the centre ignored his health condition but their reaction - asking a few questions before moving on to the next subject - was what facilitated Greg's turning point.. Greg identified "when I was like that" which illustrates how his sense of self was now different to what it was before becoming socially integrated and this support helped Greg build upon his self-esteem and self-worth. Additionally, Greg speaks informally of "the boys" which portrays a sense of camaraderie, closeness and friendship with the other fathers in the centre. The social networks in the centre not only offered a non-judgemental and supportive network but also a sense of belonging.

\section{Theme Two: Distinctive Qualities of Relationships Created in the Family Centre}

Subtheme One: Dichotomy Between Relationships Created Inside and Outside the Family Centre 
Relationships created in the centre ranged from acquaintances to close confidants, but parents proposed close friendships created in the centre as being qualitatively different from those which has been established outside the centre.

"Sitting in the group one of the times, and I remember saying to everyone like crying saying "I'm so glad to have met you" because that was like our Thursday group, when we came back, it was like a total different relationship than from what I had with my own friends. With my own friends it was kind of like "oh right let's go out" and then that all kind of stopped because I was like I just don't want to go out and stuff and be false with you and not be able to speak. Aye you don't want to go and have a pure damper on your night, but you want people to realise like how you are feeling. Erm, and being supportive for each other, if someone does need to leave or whatever. It was just great knowing that people understand your circumstances in here and would ask about you." (Nicolle)

Nicolle felt that her friends outside the centre were dismissive and unsupportive and she slowly begun to withdraw from their friendship as she felt she could not be herself. This was not uncommon and other parents mirrored Nicolle's experience, identifying that even though they had friends out with the centre, those friends were unable to meet their support needs. This meant that even when parents had friends, they could still feel isolated. In contrast, Nicolle recalls of a time she was overwhelmed with emotion related to the support she felt from her friends within the centre. There was a sense of understanding between the mothers in the group and instead of always having to actively seek support, Nicolle identified that her friends from the centre were proactive in asking about her. Throughout this extract there is a sense of gratitude related to the support she felt.

Many parents identified that the difficulties their friends outside the centre had in supporting them times of crisis when they needed support the most. 


\section{"I think a lot of people found it really hard to kind of take it, especially because of the} person I used to be, to the person I was." (Amanda)

Instead of focussing on how she felt during mental illness, Amanda illustrated the preoccupation she had with how others in her social network would perceive her. Amanda recognised that her struggles with her mental health had changed her as a person however identified that others found accepting this more difficult. Amanda proposed that this may have been "because of the person I used to be" which may be illustrative of her friends" perception that only a certain kind of person would struggle with mental health. Amanda's social networks were a source of additional stress and parents identified that a friendship which was unable to provide the support required could in turn become a source of strain. Parent's concerns about how their social networks outside the family centre would react to their mental health struggles contrasted with the support and acceptance they felt from friends within the centre.

\section{Subtheme Two: Navigating Norms}

Parents identified that over time some initial friendships fragmented to become redundant however some flourished to become part of their lives beyond the walls of the centre.

$$
\begin{aligned}
& \text { "Like I said there's other women, other mums and that, that I won't pass } \\
& \text { in the street without saying "hiya" and having a conversation but I } \\
& \text { wouldn't phone them at nine o'clock at night like "what you up to?" } \\
& \text { It's, do you know, but aye, I'd phone Hayley, and I would phone, I would } \\
& \text { phone Nicolle more so, Nicolle, aye." (Ashley) }
\end{aligned}
$$

Parents often distinguished between people they recognised from the centre and friends they had created in the centre. Ashley uses language - "other women" and "other mums", with the repetition of 'other' illustrating a separateness between herself and those women, however this contrasts with her friends who she specifically names. Ashley described no parents she knew quite well but instead identified her relationships as being very weak or very strong and this may be indicative of a hesitancy to invest social resources in 
partially developed ties. In this extract Ashley begins to describe social norms related to relationship classification which seemed to portray a social code related to what was deemed acceptable behaviour. Ashley illustrated the strength of a relationship as impacting upon social norms by contrasting her behaviour in weak social ties in comparison to strong social ties. Although Ashley emphasised distance between herself and weaker ties, she abided to certain social norms such as not passing another family centre mum in the street without acknowledging her.

Furthermore, within her close relationships with Hayley and Nicolle, Ashley illustrated that although she would call both mothers at night, she would be more comfortable in doing this with Nicolle. This highlighted that even within strong ties there was a hierarchy which influenced social norms. There was a respect for boundaries which influenced appropriate behaviour. As her relationships developed, boundaries such as not wanting to disturb someone with a late-night phone call became less prominent and this may be illustrative of the confidence Ashley had that her strong friendships would be receptive of the contact outside the family centre.

Ashley discussed later in her interview how she bonded with some mothers more than others and much was related to levels of reciprocal support within the relationship.

"She comes to my hospital appointments with me, know what I mean, and I'll maybe chum her to the hospital when her child is there." (Ashley)

The support from a relationship created within the environment of the family centre was useful in the outside world and as friendships developed parents became less dependent on waiting to come to the centre in order to engage with their friends. In this extract, Ashley speaks about Nicolle and she repeatedly discusses how support within their friendship was reciprocal. The use of the word "chum" illustrates the informality associated with the support which Nicolle and Ashley provided each other with. The give and take between Ashley and Nicolle was proposed as being a fair trade of time and support - a respect for one another. For Ashley and many other parents, it was important to return support which had been provided 
by their friends in order to maintain and reaffirm the investment all parties had in the relationship.

In contrast, some relationships which has been created in the centre struggled to maintain relevancy outside the centre and did not become integrated into parents' lives out with the centre.

"We both get in for free. And then under threes get in for free, so. And the 7 goes from here right down to outside so that's totally something we could do. But, but yeah. Little things like that, I don't know. I think, it's easier to like plan to do things than to like actually do them.

\section{But I don't know. " (India)}

The centre was a convenient place for parents to meet however parents had to rely upon themselves to arrange to meet outside the centre in order to develop and integrate friendships into their lives. Valued friendships sometimes became less important when there was the requirement for both parties to invest in making arrangements and this became a barrier to some relationships developing. Some relationships did not grow when reliant on mutual investment which may be indicative of the shared environment of the family centre as being essential in facilitating some parent's social inclusion. India could not explain why she did not meet other mothers outside the centre even after identifying all the reasons they should and confirming that it was not an unrealistic expectation. This may be illustrative of the complexity involved in parents' journeys from being socially isolated to socially integrated.

\section{Theme Three: Essential Components of Strong Friendships}

\section{Subtheme One: Trust}

Strong friendships created in the centre produced social capital including reciprocal support and trust.

"It's reassuring like, you know, I think the best experience comes from another mother. Like you know you can trust that advice because they've 
been through it. There's a sense of you are in it together type of thing. And you can work it out together." (Joanne)

Advice and emotional support were commonly identified as a product of close family centre relationships. It could be understood that other parents were viewed as being experts of their own experience and the advice they provided their peers with was rooted in experience not speculation. Joanne trusted the knowledge passed to her from other mothers and identified this advice as valid and authentic. Social networks created in the family centre were essential vehicles for the mobilisation of information and advice and without the structure of the network, information would not be able to be passed from parent to parent.

There was a sense of solidarity within friendships in the family centre and this facilitated trust. In this extract, Kara identifies her own social network within the centre as "this wee family".

"With this wee family, there's obviously more, a wee bit more understanding. And you don't feel so uptight and so em worried. That you are going to say something that they are going to judge you for, or make you feel weird." (Kara)

Kara illustrated the closeness of friendships created within the centre, identifying her social network as 'family'. In comparison with her biological family, the family-centre-family was identified by Kara as having more insight into her own situation. It was common for parents to feel responsibility in relation to their biological family and this meant that they censored themselves in front of them. This often led to problems being minimised by parents which hindered support seeking. Nonetheless, the family-centre-family offered similar intimacy without this barrier.

\section{Subtheme Two: Reciprocity}

Whilst professional support was one way, peer support was reciprocal and often based on a shared understanding which has been rooted in having their own experience of similar circumstances. 
"I think it's more of a, like if you speak to them and they know you are in the same boat kind of thing, you can talk about things, get, help each

$$
\text { other." (Leah) }
$$

Being in the "same boat" was a recurrent concept identified by parents and the phrase illuminated a sense of similarity in relation to parents' shared support needs and shared experiences. Having shared circumstances paved a level ground on which support could be reciprocally given and received. By being in the same boat and having shared experiences, parents had a sensitivity to each other's needs and this awareness facilitated reciprocal support. Although Leah did not define the areas of support which were provided through her social networks she uses a general description of support "talk about things" which may be indicative of the support provided being wide and varied. Leah corrected herself when she was speaking of support "get, help each other". It could be recognised that Leah rephrased part of the sentence to fairly illustrate that she not only sought support from her friendships created in the centre but that this support could be reciprocated. Furthermore, by changing terminology Leah recognised her own ability to give support to others thus recognising the value she had in the support network.

Furthermore, parents were not only capable of providing valuable advice to other parents but they were eager to do so.

"If I can offer any of the guys any kind of advice through stuff that I've been through that they're now starting to go through with their kinds, you know." (Greg)

Greg had been at the centre for a significant amount of time and as the sole carer for his children he was experienced in the issues many of the others dad were struggling with. Greg was a facilitator of advice within the dad's group and he took on a role of support provider to other dads who had less experience. Greg understood that his own experience gave him insight into what many of the other dads were going through and he was aware that this experiential insight was a quality unique to peer support rather than professional support. The use of the word "offer" could be illustrative of Greg not expecting anything in return for his advice 
beyond the satisfaction of knowing that he had helped other dads through his advice. This extract reiterates the use of social networks as essential in the mobilisation of knowledge. 


\section{DISCUSSION}

Parents as a demographic tends to be less well represented in the social isolation literature and findings from the current study have begun to highlight the barriers and facilitators related to parental social inclusion. All parents interviewed identified the family centre as essential in reducing their social isolation. Many parents proposed that feeling socially integrated positively impacted upon their world view and attitude and this mirrored previous literature which emphasised the positive physical and mental health outcomes of social support (Durkheim, 1951; Cohen \& Wills, 1985; Berkman et al, 2000; Cacioppo, Fowler \& Christakis, 2009). Nonetheless, becoming socially integrated was not always easy and some parents felt anxious about engaging in social networks. This finding supported previous literature which identified that individuals experiencing chronic social isolation can become stuck in a loop of negative behaviour and thought wish could push away opportunities for social contact (Cacioppo \& Patrick, 2008).

Every parent interviewed identified that they had previously experience social isolation. This supports findings from Dodds (2016) who reported high prevalence of isolation in deprived Glaswegian communities. Whilst previous literature identified centre based support as an important social resource for attendees (Donetto \& Maben, 2014; Whittaker et al, 2014), there was limited knowledge about the types of social relationships created in these centres. Current findings propose the relationships being made and developed within the family centre as being qualitatively different to those made outside the centre. Parents identified that relationships made inside the centre were less judgemental and more understanding than those created out with the centre. Additionally, some parents identified that although they previously had social networks outside of the centre, these relationships did not provide them with support. The understanding that isolation was not only related to quantity of relationships but also quality was also previously identified by Chen and Feeley (2014) who reported loneliness as being related to low quality of social relationships.

Parents were able to provide their peers with support and advice after often having been through similar circumstances. This mean that parents were not only support receivers but also support 
providers. Being a provider of support impacted positively on parent's well-being and this echoed previous research from Gale et al (2018) who identified peer-peer support networks as contributing to self-esteem. Additionally, parents identified that they trusted and valued advice from parents who had been through similar experiences and this is similar to previous findings by Thoits (1986) and Ritter (1988) who identified that individuals were more likely to engage in peer support because peers had a more complete understanding of their environment.

Although a link between social networks and social capital has been established within literature (Bourdieu, 1986; Coleman, 1988; Putnam, 2000), little was known about the specific types of social capital which could be created. Current findings mirror previous theory (Putnam, 2000) with parents identifying trust and mutual dependency as being closely related to social capital. Additionally, Bourdieu (1986) identified social capital being understood as being a product of two-way social interaction, which mirrored current findings. Trust was understood as being an essential component in the maintenance of social ties and social capital and this supported previous findings by Hawkins and Maurer (2011) who identified trust, reciprocity and social capital as being required for the development of strong relationships. Furthermore, social capital has been proposed as impacting positively on selfconcept and self-esteem (Coombs, 1969; Cohen \& Syme, 1985; Cattell, 2001) and this was reflective of current findings that identified that parents' sense of self was positively impacted as a result of creating and developing social networks.

\section{PRACTICAL IMPLICATIONS}

It is imperative that centre based services are available in the community, especially in deprived areas, in order to provide parents with the opportunity of social integration. In terms of accessibility it is essential that centre based support does not only provide statutory intervention as to do so would take away this opportunity for social integration for families who did not reach this threshold. Additionally, parents should be identified as important and effective support providers for others and parents therefore should be supported, when appropriate, to 
engage in a support providing role. Current findings have contributed to a better understanding of the social impact of centre based support in communities and have begun to build knowledge about the types of social networks which can be created and developed in these spaces which can inform our understanding about how best to support parents to become socially integrated.

\section{LIMITATIONS}

The main limitation was that the purposive sample of ten parents were self-selecting on whether they wished to take part. Other parents who attended the centre who may have had different experiences or views and fathers were underrepresented. Another limitation within study may be the difficulty in determining what specifically facilitated parents in creating and developing social networks within the centre. Factors including shared experiences and increased self-esteem were identified by parents as having a positive impact on their desire to create social relationships. Findings highlight the need for family centres to provide a range of resources for parents so they can engage with those most appropriate for their needs.

\section{CONCLUSIONS}

Family centres are a useful resource in facilitating social inclusion within deprived urban communities. Findings provide a deep insight into the lived experience of parents who attended the family centre and the impact this had on feelings of social inclusion. IPA enabled an insider's perspective with the analysis producing an authentic account of parents' lived experiences. Social inclusion created through family centre attendance impacted positively on parents' well-being and relationships provided parents with essential social support. 


\section{References}

Berkman, L. F., Glass, T., Brissette, I., \& Seeman, T. E. (2000). From social integration to health: Durkheim in the new millennium. Social Science \& Medicine, 51(6), 843-857.

Bourdieu, P. (1986). The social space and the genesis of groups. Information (International Social Science Council), 24(2), 195-220.

Cacioppo, J. T., \& Hawkley, L. C. (2009). Perceived social isolation and cognition. Trends in Cognitive Sciences, 13(10), 447-454.

Cacioppo, J. T., Fowler, J. H., \& Christakis, N. A. (2009). Alone in the crowd: The structure and spread of loneliness in a large social network. Journal of Personality and Social Psychology, 97(6), 977.

Cacioppo, J., \& Patrick, W. (2008) Loneliness: Human Nature and Need for Social Connection. Norton. New York.

Cattell, V. (2001). Poor people, poor places, and poor health: The mediating role of social networks and social capital. Social Science \& Medicine, 52(10), 1501-1516.

Chen, Y., \& Feeley, T. H. (2014). Social support, social strain, loneliness, and well-being among older adults: An analysis of the health and retirement study. Journal of Social and Personal Relationships, 31(2), 141-161.

Cohen, S., \& Wills, T. A. (1985). Stress, social support, and the buffering hypothesis. Psychological Bulletin, 98(2), 310.

Cole, I., Batty, E., \& Green, S. (2011). Low-income neighbourhoods in Britain: The gap between policy ideas and residents' realities. Joseph Rowntree Foundation.

Coleman, J. S. (1988). Social capital in the creation of human capital. American Journal of Sociology, 94, S95-S120. 
Cook, R. (2012). Social exclusion in Scotland. Scotland: The Scotland Institute.

Demakakos, P., Nunn, S., \& Nazroo, J. (2006) Loneliness, Relative Deprivation and Life Satisfaction. Retirement, Health and Relationships of the Older Population in England. Institute for Fiscal Studies.

Dodds, S. (2016). Social contexts and health. Glasgow: Glasgow Centre for Population Health.

Donetto, S., \& Maben, J. (2014). 'These places are like a godsend': A qualitative analysis of parents' experiences of health visiting outside the home and of children's centres' services. Health Expectations, 18(6), 2559-2569.

Durkheim, E. (1951). Suicide: A study in sociology. New York: The Free Press.

Gale, N. K., Kenyon, S., MacArthur, C., Jolly, K., \& Hope, L. (2018). Synthetic social support: Theorizing lay health worker interventions. Social Science \& Medicine, 196, 96-105.

Glasgow Centre for Population Health. (2011). Understanding Glasgow: The Glasgow indicators project. Glasgow: GHCP.

Hawkins, R. L., \& Maurer, K. (2011). Unravelling social capital: Disentangling a concept for social work. British Journal of Social Work, 42(2), 353-370.

Hawton, K., Harriss, L., Hodder, K., Simkin, S., \& Gunnell, D. (2001) The Influence of the Economic and Social Environment on Deliberate Self Harm and Suicide. Psychological Medicine.

Kirk, R. H. (2003). Family support: The roles of early years' centres. Children \& Society, 17(2), $85-99$.

Lewis, D. (2017). "Capturing complexity". In Brown, T.; et al. Health Geographies: A Critical Introduction. Oxford: John Wiley \& Sons, 158. 
Lewis, J., Cuthbert, R., \& Sarre, S. (2011). What are children's centres? The development of CC services, 2004-20081. Social Policy \& Administration, 45(1), 35-53.

Morrison, J., Pikhart, H., Ruiz, M., \& Goldblatt, P. (2014). Systematic review of parenting interventions in European countries aiming to reduce social inequalities in children's health and development. BMC Public Health, 14(1), 1040.

Putnam, R. D. (2000). Bowling alone: America's declining social capital. Culture and politics. Springer. New York, 223-234.

Ritter, C. (1988). Social supports, social networks, and health behaviors. Health behavior (pp. 149-161) Springer.

Scottish Government. (2011). Poverty and income inequality in Scotland: 20092010. Edinburgh: Scottish Government.

Scottish Government. (2016). Scottish index of multiple deprivation (SMID)2016. Edinburgh: Scottish Government.

Scottish Government. (2018). Poverty \& income inequality in Scotland: 2014-17. Edinburgh: National Statistics. Retrieved from http://www.gov.scot/Resource/0053/00533112.pdf

Sheppard, M. (2012). Preventive orientations in children's centres: A study of centre managers. British Journal of Social Work, 42(2), 265-282.

Smith, J. A. (2004). Reflecting on the development of interpretative phenomenological analysis and its contribution to qualitative research in psychology. Qualitative Research in Psychology, 1(1), 39-54.

Smith, J., Flowers, P., \& Larkin, M. (2009). Interpretative phenomenological analysis: Theory, method and research. London: Sage. 
Smith, K. P., \& Christakis, N. A. (2008). Social networks and health. Annual Review of Sociology, 34, 405-429.

Thoits, P. A. (1986). Social support as coping assistance. Journal of Consulting and Clinical Psychology, 54(4), 416.

Umberson, D., \& Montez, J. K. (2010). Social relationships and health: A flashpoint for health policy. Journal of Health and Social Behavior, 51 Suppl, S54-66.

United Nations. (2016). Identifying social inclusion and exclusion. New York: United Nations. Retrieved from http://www.un.org/esa/socdev/rwss/2016/chapter1.pdf

Warren-Adamson, C. (2006). Research review: Family centres: A review of the literature. Child \& Family Social Work, 11(2), 171-182.

Whittaker, K. A., Cox, P., Thomas, N., \& Cocker, K. (2014). A qualitative study of parents' experiences using family support services: Applying the concept of surface and depth. Health \& Social Care in the Community, 22(5), 479-487.

Wilkinson, R. G., \& Marmot, M. G. (2003). Social determinants of health: The solid facts World Health Organization.

Wilks, S. E., \& Croom, B. (2008). Perceived stress and resilience in Alzheimer's disease caregivers: Testing moderation and mediation models of social support. Aging and Mental Health, 12(3), 357-365. 